\title{
Born solution providers - Dynamic capabilities for providing solutions
}

Caroline Jennings Saul and Heiko Gebauer

The self-archived postprint version of this journal article is available at Linköping University Institutional Repository (DiVA):

http://urn.kb.se/resolve?urn=urn:nbn:se:liu:diva-151803

N.B.: When citing this work, cite the original publication.

Saul, C. J., Gebauer, H., (2018), Born solution providers - Dynamic capabilities for providing solutions, Industrial Marketing Management, 73, 31-46. https://doi.org/10.1016/j.indmarman.2018.01.007

Original publication available at:

https://doi.org/10.1016/j.indmarman.2018.01.007

Copyright: Elsevier

http://www.elsevier.com/

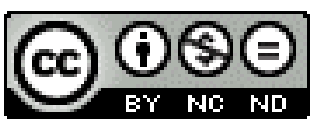


Target and position article

\title{
Born solution providers - Dynamic capabilities for providing solutions
}

\author{
Caroline Jennings Saul ${ }^{\mathrm{a}, \mathrm{b}}$, Heiko Gebauer ${ }^{\mathrm{a}, \mathrm{b}, \mathrm{c}, *}$ \\ ${ }^{a}$ Eawag/Environmental Social Sciences/Business Innovation for Sustainable Infrastructure Services Group, Eawag, Überlandstrasse 133, 8600 Dübendorf, Switzerland \\ ${ }^{\mathrm{b}}$ CTF, Service Research Center, Karlstad University, Sweden \\ ${ }^{\mathrm{c}}$ Linköping University, Sweden
}

\section{A R T I C L E I N F O}

\section{Keywords:}

Solution providers

Services in product companies

Dynamic capabilities

Emerging markets

\begin{abstract}
A B S T R A C T
Our investigation draws on a qualitative study, which explores the anomaly of Born Solution Providers. Compared to the traditional assumption that product companies shift toward solutions during the maturity phase, companies can already offer solutions in the market development phase. We investigate the dynamic capabilities for providing solutions in the market development phase. Our findings reveal a microfoundation of dynamic capabilities. This microfoundation is structured into 10 dimensions along sensing, seizing, and reconfiguring activities. Within these 10 dimensions, we disaggregate the dynamic capabilities into individual skills and organizational routines. Interestingly, organizations utilize routines underlying the options for each dimension (e.g., routines for sensing internal and external opportunities, seizing standardization, and customization), but they tend to stick to routines for one of these options. Individual skills enable organizations to balance the options. Our results suggest that these individual skills evolve through higher-order processes, namely, single- and double-loop learning activities.
\end{abstract}

\section{Introduction}

Product companies increasingly bundle products and services into solution offerings, rather than selling only products (Davies, Brady, \& Hobday, 2006; Sawhney, Balasubramanian, \& Krishnan, 2003; Tuli, Kohli, \& Bharadwaj, 2007). As solution providers, companies can increase their revenue, profitability, and customer satisfaction (Cusumano, Kahl, \& Suarez, 2015; Eggert, Hogreve, Ulaga, \& Muenkhoff, 2014; Ulaga \& Reinartz, 2011). Existing research has typically assumed that product companies differentiate themselves increasingly through customer solutions, as product markets increasingly reach the maturity phase (i.e., increasing competition and eroding product margins) (Matthyssens, Vandenbempt, \& Berghman, 2006). However, there is also an interesting anomaly (Kuhn, 1970) to this assumption, which we call Born Solution Providers. Instead of waiting until product markets reach the maturity phase, born solution providers provide solution offerings already in the market development phase.

Xerox is an example of such a born solution provider in the market development phase for photocopier machines. When Xerox introduced its first plain paper photocopier machines, it was not merely a product firm selling new machines together with services (e.g., spare parts, repair service), and in doing so representing a substantial shift toward solutions in the maturity phase. Instead, Xerox was a born solution provider, bundling products and services such as maintenance, repair, insurance, and pay-per-copier usage services (e.g., paying for copies) into solutions in the market development phase.

During market development, born solution providers face a situation in which customer needs and the competitive situation are still in a state of flux, leading to frequent changes in the business environment. Product technology is still relatively immature, which makes the provision of customer solutions difficult (Cusumano et al., 2015). Thus, dynamic capabilities such as the ability to respond to changes in the business environment are a key success factor (Eisenhardt \& Martin, 2000; Teece, 2007; Zahra \& George, 2002).

We apply a theoretical perspective on dynamic capabilities to born solution providers. We focus on companies attempting to enter emerging markets during the market development phase. By answering the research question "Which dynamic capabilities enable product companies to become born solution providers?", our study makes the following contributions to the literature. We broaden the empirical focus to the market development phase and to emerging markets (Luoto, Brax, \& Kohtamäki, 2016). Born solution providers prevail existing theoretical assumptions. We advance the research on solutions and services in product companies from its current, nascent, theoretical stage to a more mature stage (Kowalkowski, Gebauer, \& Oliva, 2017). Furthermore, we provide a microfoundation of dynamic capabilities in terms of individual skills and organizational routines (Stefano et al., 2010; Teece, 2007).

\footnotetext{
* Corresponding author at: Linköping University, Division of Business Administration, Department of Management and Economics (IEI), Sweden.

E-mail addresses: caroline.saul@eawag.ch (C.J. Saul), heiko.gebauer@eawag.ch (H. Gebauer).
} 


\section{Theoretical background}

\subsection{Born solution providers}

Solution providers are defined as product companies that bundle products and services into solution offerings, rather than selling only products (Davies et al., 2006; Sawhney et al., 2003; Tuli et al., 2007). Solutions are "individualized offers for complex customer problems that are interactively designed and whose components offer an integrative added value by combining products and/or services so that the value is more than the sum of the components" (Evanschitzky, van Wangenheim, \& Woisetschläger, 2011, p. 657). In other words, "a solution provider integrates goods, service and knowledge components into unique combinations that solve strategically important customer specific problems" (Storbacka, 2011, p. 699).

Differentiation through solutions becomes increasingly important as companies proceed through the market development, growth, and maturity phases. Specifically, increasing price competition, eroding product margins, and commoditization tendencies associated with the maturity phase compel product companies to move toward solutions (e.g., Davies, 2004; Galbraith, 2002; Storbacka, 2011). Born solution providers do not wait until product markets reach the maturity phase, but provide solution offerings as early as the market development phase.

The market development phase describes the early stage in a product life cycle, a phase also termed the "ferment" and/or introductory phase (Cusumano et al., 2015; Kotler \& Armstrong, 2010). During this phase, product technology is new, and it is unclear to customers and producers how products will perform, what problems will emerge during the product usage, and what product characteristics will be important for attracting customers and optimizing life-cycle costs. Further difficulties arise because these companies have little knowledge of customer needs that will arise during product usage. Products are simply too new for the company to gain insights into providing solutions to improve efficiency and effectiveness for product usage and/or for addressing strategic customer needs. Even if companies were to provide such solutions, they would be less likely to pay off, because the installed product base is still too low to provide the solutions in a costefficient manner (Cohen, Agrawal, \& Agrawal, 2006; Fang, Palmatier, \& Steenkamp, 2008).

Of course, emerging markets are promising for born solution providers because they offer attractive growth rates and often exhibit relatively little competition. However, emerging markets make product technologies even more uncertain. Born solution providers face a situation in which it remains unclear whether technologies developed in industrialized markets are readily applicable to emerging markets (London \& Hart, 2004). Customers in emerging markets are quite sensitive to price, which puts even more emphasis on cost and functionality.

\subsection{Dynamic capabilities}

While operational capabilities enable companies to earn a living in a specific business environment (Winter, 2003; Zahra, Sapienza, \& Davidsson, 2006), the dynamic-capability view considers explicitly how the external business environment influences the capabilities and how they are transformed into competitive advantages (Priem \& Butler, 2001; Teece, Pisano, \& Shuen, 1997). Dynamic capabilities refer to a firm's ability to integrate, build, and reconfigure competences, so as to address rapidly changing business environments (Eisenhardt \& Martin, 2000; Teece et al., 1997). Zollo and Winter (2002, p. 340) defined dynamic capabilities as "a learned and stable pattern of collective activity through which the organization systematically generates and modifies its operating routines in pursuit of improved effectiveness." Similarly, Helfat et al. (2007, p. 4) stated that "a dynamic capability is the capacity of an organization to purposefully create, extend, and modify" its operational capabilities. Dynamic capabilities are vital for anticipating, enforcing, and responding to changes in the business environment and for altering operational capabilities.

Conceptualizations of dynamic capabilities distinguish, for example, between adaptive, absorptive, and innovative capabilities (Wang \& Ahmed, 2007) as well as between renewing, incremental, and regenerative ones (Ambrosini, Bowman, \& Collier, 2009). Dynamic capabilities involve three activities: sensing opportunities and threats, as well as the need to change; seizing the opportunities sensed and fending off threats; and reconfiguring operational capabilities to maintain competitiveness (Teece, 2007). Underpinning these three generic capabilities are microfoundations, defined by Teece (2007, p. 1319) as "distinct skills, processes, procedures, organizational structures, decision rules, and disciplines."

Accordingly, this microfoundation includes individual skills and organizational routines. The latter originates from the literature on routines driving corporate development (March, 1991). Routines are rules, tools, and procedures that companies apply (Felin \& Foss, 2009). Individual skills capture the attitudes, expertise, and cognitive skills (e.g., managerial foresight, instrumental cognition, or entrepreneurial alertness). Sensing, seizing, and reconfiguring activities are the "ingredients" of dynamic capabilities (Eisenhardt \& Martin, 2000), whereas the organizational routines and individual skills are the "recipe" that creates dynamic capabilities (Newbert, 2005).

Sensing new opportunities involves searching processes, which are related to the business environment (Teece, 2007). The sensing capability is similar to the notion of market-focused learning, which refers to a firm's market-searching effort and is connected to the processes enabling a firm to anticipate market developments and customer requirements, needs, and preferences (Weerawardena \& O'Cass, 2004). Seizing captures how companies address and take advantage of the sensed opportunity by conducting activities, such as delineating the products and services, as well as defining the most suitable business model for taking advantage of opportunities (Teece, 2007). Seizing also refers to fully utilizing investments in the sensed opportunities (Helfat \& Peteraf, 2009). Reconfiguring enables companies to continuously realign the operational capabilities with the seized opportunities, and is about altering existing operational capabilities and creating new ones (Weerawardena \& O'Cass, 2004).

\subsection{Dynamic capabilities for providing solutions}

Despite their vital role, there has so far been little research on dynamic capabilities for moving toward solutions. Existing research derives dynamic capabilities either from general discussions on capabilities for moving toward solutions, or discussions on dynamic capabilities for extending the service offering (see Table 1).

\subsubsection{Capabilities for providing solutions}

Researchers generally agree that compared to product companies, solution providers must reconfigure multiple capabilities to address a broader set of heterogeneous customer segments and diversified customer needs. Such multiple capabilities cover system integration, production, delivery, technical application, partnering, marketing, and business consulting competences (Ceci \& Prencipe, 2008; Davies, 2004; Shepherd \& Ahmed, 2000). Besides the positive association between providing solutions and competitive advantages, there is a risk that developing such multiple capabilities may dilute core competences and ultimately erode competitive advantages (Ceci \& Masini, 2011).

Providing solutions requires capabilities for seizing the organizations so as to become more customer-centric; to customize solutions (e.g., personalized packages for service, support, education, consulting); and to manage organizations in the context of customer segments, teams, and profit and losses. Solutions demand convergent thinking, which combines products and services in a way that is best for customers (Galbraith, 2002). 
Table 1

Overview on selected contribution of capabilities for providing solutions and dynamic capabilities for providing services.

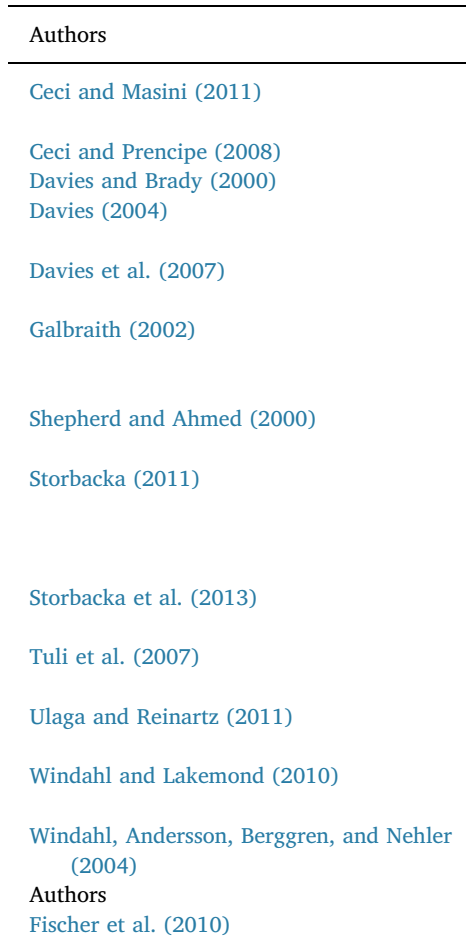

Capability descriptions for providing solutions

Capabilities related to hardware and infrastructure manufacturing, software development, consulting, financing, delivery, postsales support, and system integration

Capabilities for system integration, consulting, operational, production, and delivery as well as in-house managed activities Strategic capabilities, functional capabilities, and project capabilities

Developing novel combinations of service capabilities (operation, business consultancy, and finance) required to tailor solutions to individual customer needs.

Ability to integrate a range of components from a variety of internal and external suppliers is becoming the core activity required to provide integrated solutions.

Abilities to make organizations more customer-centric (e.g., customizing solutions, managing customer portfolio and profitability, tailoring solution packages in terms of service, support, education, and consulting, empowering people with in-depth knowledge on customer's business

Technical and application competence, partnering competence, marketing and business consulting competence, system integration competence.

Capability categories: 'develop solutions': value research and solutions development; 'create demand': value proposition and solutions availability; for 'sell solution': value quantification and solution configuration; and, for 'deliver solution': value verification and solution delivery. Additional four capability categories: strategy planning, management system, infrastructure support, and human resources management.

Solution business requires abilities for managing the interrelations and interconnection among customer embeddedness, operational adaptiveness, offering integratedness and (4) organizational networkedness

Abilities for customer requirements definition, customization and integration of goods and/or services and their deployment, and postdeployment customer support

Service-related data processing and interpretation capability, risk assessment and mitigation capability, design-to-service capability, sales capability for hybrid offerings, and deployment capability for hybrid offerings.

Ability to balance elements of both goods- and service-logics, as well as manage the increased customer-supplier interdependencies that integrated solutions entail.

Balancing competences such as technical and application competence, partnering competence, system integration competence, and market/business \& consulting competence.

Descriptions on dynamic capabilities for providing services

Approaches for service business development (Exploitation)

Phase 1: Integrating basic services into the product price: forming a dominant design (tactical choices on bundling and charging goods and services)

Phase 2: Separating product and service business to extend service profit and revenue: commercializing services that were originally included in the product prices and creating a distinct service business (business manager qualities)

Phase 3: Making use of the service expansion along the primary customer activity chain: satisfying customers' expressed needs, formulating "planned strategies", articulating intended strategies, responding to customer needs and competitors' service offerings

Approaches for service business development (Exploration)

Phase 1: integrating basic services into the product price: Forming a dominant design (tactical choices on bundling and charging goods and services)

Phase 2: Creating a new value constellation: visioning new value opportunities, articulating" umbrella strategies" for the new value constellations, allowing various scenarios to emerge, exploring a broad range of different business opportunities Phase 3: Making use of the service expansion along the adjacent customer activity chain: Supporting customers' primary and adjacent activity chains, stabilizing the new value constellation, involving rigid scenario planning, respond to customer needs and competitors' offerings

Den Hertog et al. (2010)

Signaling user needs and technology options, conceptualizing, (un-)bundling capability, co-producing and orchestrating, scaling and stretching, and learning and adapting.

Sensing capabilities: customer-linked service sensing, service system sensing, internal sensing, and technology exploration Seizing capabilities: service interactions, managing the service delivery process, structuring the service development process, and adopting new revenue mechanisms

Reconfiguring capabilities: orchestrating service system, balancing product- and service-innovation related assets, developing of a service-oriented mental model

Commercialization: regular planning with customers, quantifying customer value, contract models for lead customer involvement etc.

Industrialization: Tools linking customer processes and financial drivers, ERP (Enterprise Resource Planning) and product data management system coding the standardized solution elements, rules for structuring solutions and for flexible adaptations etc. Solution platform: Segmenting strategies (business goals are set and followed up), risk assessment tool, solution portfolio management etc

Create demand:

Commercialization: role profiles, campaign plans for sales staff etc.

Industrialization: solution configurations for different segments, value pricing approach (not cost plus) etc.

Solution platform: cross-functional teams, metrics for measuring and managing solution business etc

Sell solution:

Commercialization: configuration tools, risks factored into the pricing, customer-specific value propositions etc.

Industrialization: solution configurators, contract models, business case analysis, standard costing data on solutions and individual solution elements etc.

Solution platform: ERP systems to manage the solution delivery, specialized intelligence unit to support sales, CRM system supporting solution sales etc.

Value verification:

Commercialization: sales process ensuring accurate input to the order-delivery process, contract handover mechanisms, procedures for measuring customer profitability etc.

Industrialization: communication interfaces with partners, monitoring tools for the delivery and for corrective actions, network partner roles etc.

Solution platform: bonus schemes rewarding cross-functional teamwork, skill profiles that relate to solution delivery etc. 
Table 1 (continued)

\begin{tabular}{ll}
\hline Authors & Capability descriptions for providing solutions \\
\hline Lenka et al. (2017) & $\begin{array}{l}\text { Microfoundations in terms of individual tactics (i.e., evangelizing, bootlegging, leveraging, and collaborating) for overcoming } \\
\text { organizational resistance to providing advanced services. }\end{array}$
\end{tabular}

Further examples include studies by Ulaga and Reinartz (2011) on distinctive capabilities for hybrid offerings (combinations of products and services) and by Tuli et al. (2007) on customer solutions. Ulaga and Reinartz (2011) highlighted the importance of service-related data processing as well as interpretation capability, execution risk assessment and mitigation capability, design-to-service capability, hybrid offering sales capability, and deployment capability.

Suppliers and customers view a solution as a set of relational processes, comprising abilities for sensing customer requirements, customizing and integrating products and/or services, and providing comprehensive customer support (Tuli et al., 2007). These abilities make it possible to meet customer needs and to deliver solutions cost effectively (Penttinen \& Palmer, 2007; Storbacka, Windahl, Nenonen, \& Salonen, 2013).

Cost-effectiveness requires repeatable solutions, for which repetition would facilitate mastering the learning curve quickly (Davies \& Brady, 2000; Storbacka, 2011). Strategic, functional, and project capabilities enable companies to move successfully toward such repeatable solutions. Strategic capabilities are similar to the notion of dynamic capabilities, enabling companies to respond to and shape changes in their environments (Chandler, 1990). Functional activities are necessary for survival, representing "core" capabilities that enable a firm to achieve competitive advantage. Project capabilities refer to activities (e.g., project design, implementation, and decommissioning) involved in providing solutions (e.g., Davies \& Brady, 2000). Similarly, Storbacka (2011) argued that solution providers need capabilities for commercializing and industrializing solutions across the phases of developing solutions, creating demand, selling solutions, and delivering them.

To develop such solution capabilities, product companies must cope with the risk that solution capabilities may dilute core competences and subject the firm to the competency trap. This trap means that due to changes in the business environment, product capabilities become more and more obsolete as a means of achieving competitive advantages (Leonard-Barton, 1992; Teece et al., 1997). Nevertheless, product companies continue to specialize in these capabilities. Existing product capabilities can be "sticky" and difficult to modify, because firms are characterized by a degree of organizational inertia that constrains change toward solutions (Ceci \& Masini, 2011). Dynamic capabilities counter this effect by allowing a product firm to reconfigure its capabilities through introducing new solution capabilities.

\subsubsection{Dynamic capabilities for services in product companies}

Existing contributions include: (i) the identification of dynamic capabilities for service innovations; (ii) the sensing, seizing, and reconfiguration framework for service innovation; (iii) the exploration and exploitation of the service business; (iv) management practices for providing solutions; and (v) the tactics overcoming the organizational resistance to providing solutions.

The latter includes routines and skills for evangelizing, bootlegging, leveraging, and collaborating, which individuals adopt to overcome organizational resistance to servitization (Lenka et al., 2017). Storbacka (2011) highlighted the necessary management practices for developing, creating, selling, and delivering solutions, e.g., competence profiles for roles relating to solution sales, customer relationship management systems supporting solution sales, or guidelines for differentiating prices between segments and customers. These practices (routines) enable the commercialization and industrialization of solutions as well as building a solution platform.
Den Hertog, van der Aa, and de Jong (2010) suggested that six dynamic capabilities improve the management of service innovations: (i) signaling user needs and technology options; (ii) conceptualizing; (iii) (un-)bundling capability; (iv) coproducing and orchestrating; (v) scaling and stretching; and (vi) learning and adapting. Signaling user needs is the ability to empathically understand users and sense their (potential) needs well in advance, by interacting intensively with (potential) clients. Signaling user needs is similar to Tuli et al.'s (2007) notion of defining customer requirements. Technology options are about new ways of interacting with customers, often by the utilization of self-service technologies. Conceptualizing is about the creative process of applying customer needs and technology options in a service concept. Such a service concept would capture single-service elements, services, and the "servicescape."

(Un-)bundling is about recombining the existing service elements into new services (Storbacka et al., 2013). This captures the abilities to combine individual services into customized service packages (solutions) and to strip down such customized solutions into highly specialized services, and to some extent standardized ones. Coproducing and orchestrating imply that a service provider has to manage an accompanying alliance with other suppliers, which actively codesign and coproduce a service innovation (Den Hertog et al., 2010).

Scaling and stretching abilities address the challenges of introducing services on a large scale in a uniform way, due to their human component, which is difficult to standardize (Lyons, Chatman, \& Joyce, 2007). This ability is important in early market development, which needs to balance growth in the product base and an extension of the organizational network (Windahl \& Lakemond, 2006). Finally, learning and adapting are about deliberately benefiting from the way service innovations are managed currently, and subsequently modifying and improving the service innovation process (Den Hertog et al., 2010). This is consistent with the general idea that learning refers to a higherorder capability guiding the evolution of dynamic capabilities (Zollo \& Winter, 2002).

Kindström, Kowalkowski, and Sandberg (2013) broke down the dynamic capabilities for service innovation of manufacturing companies into sensing, seizing, and reconfiguring activities. Sensing activities cover four main areas: (i) customer-linked service sensing, (ii) service system sensing, (iii) internal sensing, and (iv) technology exploration. Seizing activities refer to service interactions, managing the service delivery process, structuring the service development process, and adopting new revenue mechanisms. Reconfiguring activities cover orchestrating the service system, balancing product and service innovation, and (iii) developing a service-oriented mental model. Some of these dynamic capabilities coevolve with operational capabilities. For example, service system sensing and orchestrating service systems represent the necessary dynamic capabilities for altering the networking capabilities (Sjödin, Parida, \& Kohtamäki, 2016). Networking capabilities are important, because solutions quite often consist of product and service components, which are provided in collaboration with suppliers (Davies, Brady, \& Hobday, 2007).

Finally, Fischer, Gebauer, Gregory, Ren, and Fleisch (2010) applied the sequence of sensing, seizing, and reconfiguring activities to two strategic approaches for extending the service business: exploitation and exploration. As highlighted in Table 1, exploitation and exploration require a specific set of dynamic capabilities, which include both the "ingredients" of dynamic capabilities (e.g., sensing, seizing, and reconfiguring) as well as the "recipe" on routines and skills (Fischer et al., 2010; Gebauer, 2011; Kindström et al., 2013). Overall, the combination 
of ingredients and recipe determine the new firm formation of born solution providers in regard to market development (Newbert, 2005).

\subsection{Research gap and question}

Despite these descriptions of dynamic capabilities, it remains unclear which dynamic capabilities enable product companies to become born solution providers in the market development phase. This, then, is precisely our research question: Which dynamic capabilities enable product companies to become born solution providers?

\section{Research methodology}

To answer this research question, our study aims to identify the key microfoundations that enable companies to build the dynamic capabilities needed to become born solution providers. Given the relatively sparse literature on the dynamic capabilities of born solution providers, we use a qualitative, discovery-oriented research approach (Glaser \& Strauss, 2009).

This research design was chosen in order to exemplify and investigate the necessary dynamic capabilities for becoming a born solution provider. An in-depth, qualitative case study has frequently been proposed as the appropriate way to explore a novel area of research and to solidify initial conceptual considerations (Forkmann, Ramos, Henneberg, \& Naudé, 2017).

\subsection{Data sample}

In line with current calls for research on emerging markets (e.g., Kowalkowski et al., 2017), companies providing decentralized systems for water and energy are our unit of analysis. These systems are offered in geographic areas of emerging markets that, for cost reasons, are not connected to the central electricity grid and water network.

We used a purposeful sampling process (Yin, 1994), contacting 11 system providers, of whom seven agreed to participate in our study (ALPHA to ETA). We kept all company names confidential and used a "replication" rather than "statistical" logic. The number of cases is in line with Eisenhardt's (1989) recommendation to sample between four and 10 case studies.

Our seven case companies are small- and medium-sized, in which sales growth leads to an increasing number of installed systems. Our cases do not present companies favoring project-based production, which is confined to low volume, or to tailoring products to unique customer needs. Our case studies attempt to grow the sales volume (Davies \& Brady, 2000), and they are system integrators, meaning that they buy and assemble components in water and energy systems (Davies et al., 2007).

As shown in Table 2, we aimed for diversity in terms of the geographical location of the emerging markets and company headquarters as well as the industry sector. Our seven companies are headquartered in Germany, India, Switzerland, and the United States. They sell their systems to emerging markets such as India, Kenya, Nepal, Senegal, Tanzania, and Uganda. Our industry sectors include water treatment, solar, and biogas systems, which are all in the early phase of market development.

As born solution providers, these seven companies provide solutions to all customers. The solutions include a variety of components, which are configured into water and energy systems. Relevant services include ensuring system functionality, optimizing customer efficiency and effectiveness, and addressing customers' strategic and business needs. Services cover the entire life cycle, ranging from customer requirement definition in the pre-sales phases, customization and integration of products and services in the sales phases, delivery of services during product usage, and services ensuring post-deployment customer support. An important solution element is the pay-per-use payment structure, which means that customers do not purchase the solutions but pay for the outcome (i.e., water or energy consumption).

\subsection{Data collection}

We gathered data through in-depth interviews with key decision makers. For each case study, we conducted one to three interviews, resulting in a total of 16 . This number was considered as the point at which theoretical saturation is reached, because our results were upheld for the majority of organizations and made sense on the basis of prior research (Yin, 1994).

Because we relied on key informants, we interviewed decision makers who played a vital role in the process of becoming born solution providers. The interviews lasted about an hour each, and were semistructured, providing a guideline for identifying the dynamic capabilities. Our interview guideline included questions requesting clarification, examples of routines and skills, and more details on potentially useful microfoundations of dynamic capabilities. All interviews were transcribed verbatim.

In the first part of the interview, we asked for details on how our case companies became born solution providers. Thus, we gained an understanding of each company and its efforts to innovate customerspecific solutions. In the second part, respondents indicated the necessary capabilities for providing solutions. To facilitate the process, we asked participants to provide examples of specific successes and failures associated with solutions. We attempted to understand how certain dynamic capabilities (routines and skills) for sensing, seizing, and reconfiguring activities may contribute to the success of providing solutions and how the lack of them may lead to failure.

We phrased questions in an unobtrusive and nondirective manner, so as to avoid the pitfalls of excessively active listening (McCracken, 1988). We facilitated the emergence of microfoundations for dynamic capabilities, grounded in the managers' own language. The interviews concluded with respondents describing themselves and their professional background. In addition, an extensive set of secondary data was collected (internal documents such as reports and presentation material; and public material such as articles, publicly available statistics, business reports, and the company websites). Our primary and secondary data were compiled into case write-ups, which were used for data analysis and interpretation.

\subsection{Data analysis and interpretation}

A software package for qualitative research assisted us in data analysis and interpretation. We started with an analysis of each case write-up before conducting a cross-comparison. We used a grounded theory approach to identify dynamic capabilities (Strauss \& Corbin, 1998). We relied on open coding, in which we first read through the case write-ups. Independent judges verified the accuracy of the coding. As a reliability indicator, we measured the proportional agreement between the judges. A high interjudge agreement of 0.87 indicated high reliability of our coding (Rust \& Cooil, 1994).

Next we listed the critical dynamic capabilities. Specifically, we listed the identified dynamic capabilities (e.g., individual skills and organizational routines), then defined each construct, specified its characteristics, and supported the construct with an example. Furthermore, we included only dynamic capabilities that fulfilled the following criteria: (i) the insight into a dynamic capability is applicable beyond the context of one participating firm; (ii) multiple participants mentioned the capability; and (iii) the dynamic capability is useful for theory building.

To enhance content validity, we also provided the participants with summaries of the interviews and with the emerging microfoundation for dynamic capabilities. Participants returned comments, indicating their agreement with the structure of our routines and skills regarding the sensing, seizing, and reconfiguring activities, and on several occasions they suggested small changes to the wording, so as to increase 
Table 2

Sample characteristics.

\begin{tabular}{|c|c|c|c|c|c|}
\hline Case & $\begin{array}{l}\text { Interview } \\
\text { number }\end{array}$ & $\begin{array}{l}\text { Interviewee } \\
\text { function }\end{array}$ & $\begin{array}{l}\text { Company HQ/ } \\
\text { Emerging market }\end{array}$ & $\begin{array}{l}\text { Number of solutions } \\
\text { provided/Number of } \\
\text { employees }\end{array}$ & Type of systems/solution \\
\hline ALPHA & $\begin{array}{l}1 \\
2 \\
3\end{array}$ & $\begin{array}{l}\text { CEO } \\
\text { Local manager } \\
\text { Marketing } \\
\text { manager }\end{array}$ & Switzerland/Nepal & $640 / 5$ & $\begin{array}{l}\text { - Water treatment and energy production components and systems } \\
\text { - Feasibility studies on water source and water treatment technologies } \\
\text { - Franchise model for attracting entrepreneurs to operate water } \\
\text { treatment and energy production systems } \\
\text { - Supporting franchisees in system maintenance, marketing of water and } \\
\text { energy services, developing and managing water distribution services } \\
\text { - Franchisee fee is based on water and energy consumption (pay-per- } \\
\text { cubic-meter and kilowatt hour) } \\
\text { - Self-diagnosis services and remote monitoring services embedded in the } \\
\text { systems }\end{array}$ \\
\hline BETA & $\begin{array}{l}4 \\
5\end{array}$ & $\begin{array}{l}\text { CEO } \\
\text { Technical } \\
\text { assistant }\end{array}$ & Switzerland/Senegal & $120 / 9$ & $\begin{array}{l}\text { Safe drinking water solutions } \\
\text { - Water treatment components and systems } \\
\text { - Feasibility studies on water source and water treatment technologies } \\
\text { - Franchise model for attracting entrepreneurs to operate water } \\
\text { treatment systems } \\
\text { - Supporting franchisees in system maintenance, marketing of water, } \\
\text { business consulting on how to build water businesses, advise on } \\
\text { developing and managing water distribution services } \\
\text { - Franchisee fee is based on water (pay-per-cubic-meter) } \\
\text { - Self-diagnosis services and remote monitoring services embedded in the } \\
\text { systems }\end{array}$ \\
\hline GAMMA & $\begin{array}{l}6 \\
7 \\
8\end{array}$ & $\begin{array}{l}\text { CEO } \\
\text { Sales Manager } \\
\text { COO }\end{array}$ & United States/India & $500 / 20$ & $\begin{array}{l}\text { Safe drinking water solutions } \\
\text { - Water treatment components and systems } \\
\text { - Feasibility studies on water source and water treatment technologies } \\
\text { - Franchise model for attracting entrepreneurs to operate water } \\
\text { treatment systems } \\
\text { - Supporting franchisees in system maintenance, marketing of water, } \\
\text { business consulting on how to build water businesses, advise on } \\
\text { developing and managing water distribution services } \\
\text { - Franchisee fee is based on water (pay-per-cubic-meter) } \\
\text { - Self-diagnosis services and remote monitoring services embedded in the } \\
\text { systems }\end{array}$ \\
\hline DELTA & $\begin{array}{l}9 \\
10 \\
11\end{array}$ & $\begin{array}{l}\text { Technical } \\
\text { manager } \\
\text { Regional manager } \\
\text { Sales manager }\end{array}$ & Germany/Ethiopia & $450 / 35$ & $\begin{array}{l}\text { Solar home solutions for rural villages } \\
\text { - Solar panels batteries integrated into solar home solution services } \\
\text { - Electric devices and financing services for electricity consumption } \\
\text { - Consulting on electricity production and consumption } \\
\text { - Mobile payment services to pay for the electricity consumption (pay- } \\
\text { per-kilowatt hour) } \\
\text { - Remote monitoring services embedded in the solar home systems } \\
\text { - Field service and maintenance supporting the system operation }\end{array}$ \\
\hline EPSILON & 12 & President & Switzerland/India & $70 / 25$ & $\begin{array}{l}\text { Decentralized energy production solutions } \\
\text { - Feasibility study on most efficient technologies } \\
\text { - Providing biogas, solar power and wind turbine components and } \\
\text { systems } \\
\text { - Integrating the systems into tailored solutions } \\
\text { - Consulting services for setting up the electricity production and } \\
\text { consumption systems } \\
\text { - Financing services for electricity consumption systems } \\
\text { - Planning, implementing, and adapting electricity grids } \\
\text { - Peak load management for the electricity grid } \\
\text { - Remote monitoring services to continuously monitor electricity grids } \\
\text { - Payment services relying on pay-per-kilowatt hour }\end{array}$ \\
\hline ZETA & $\begin{array}{l}13 \\
14\end{array}$ & $\begin{array}{l}\text { CEO } \\
\text { Sales Manager }\end{array}$ & $\begin{array}{l}\text { Germany/Tanzania \& } \\
\text { Kenia }\end{array}$ & $7000 / 150$ & $\begin{array}{l}\text { Decentralized energy production system using solar technologies } \\
\text { - Solar panels batteries integrated into solar home solution services } \\
\text { - Electric devices and financing services for electricity consumption } \\
\text { - Consulting on electricity production and consumption } \\
\text { - Mobile payment services to pay for the electricity consumption (pay- } \\
\text { per-kilowatt hour) } \\
\text { - Remote monitoring services embedded in the solar home systems } \\
\text { - Field service and maintenance supporting the system operation }\end{array}$ \\
\hline ETA & $\begin{array}{l}15 \\
16\end{array}$ & $\begin{array}{l}\text { Sales Manager } \\
\text { Technical } \\
\text { Manager }\end{array}$ & $\begin{array}{l}\text { Germany/Tanzania \& } \\
\text { Kenia }\end{array}$ & $1000 / 45$ & $\begin{array}{l}\text { Decentralized energy production system using solar technologies } \\
\text { - Solar panels batteries integrated into solar home solution services } \\
\text { - Electric devices and financing services for electricity consumption } \\
\text { - Consulting on electricity production and consumption }\end{array}$ \\
\hline
\end{tabular}


Table 2 (continued)

\begin{tabular}{|c|c|c|c|c|c|}
\hline Case & $\begin{array}{l}\text { Interview } \\
\text { number }\end{array}$ & $\begin{array}{l}\text { Interviewee } \\
\text { function }\end{array}$ & $\begin{array}{l}\text { Company HQ/ } \\
\text { Emerging market }\end{array}$ & $\begin{array}{l}\text { Number of solutions } \\
\text { provided/Number of } \\
\text { employees }\end{array}$ & Type of systems/solution \\
\hline
\end{tabular}

- Mobile payment services to pay for the electricity consumption (payper-kilowatt hour)

- Remote monitoring services embedded in the solar home systems

- Field service and maintenance supporting the system operation

conceptual clarity. Finally, we presented and discussed our preliminary findings in a group discussion, in which participants shared their views on our proposed dynamic capabilities.

The process of synthesizing our findings was governed by a set of principles (i.e., conformability, integrity, pre-understanding, and dependability) to which interpretive research commonly adheres (Lincoln \& Guba, 1985). To reduce researcher bias (conformability) and ensure that the results are an acceptable and reliable representation of the data (integrity), we applied a three-stage series of interactions among the research team members. First, we articulated our own pre-understanding (Storbacka et al., 2013). This understanding exhibited a range: some of the research team members had 15 years of research interest in the solution business, whereas others had just started their research. Second, we used triangulation (data and investigator triangulation) to produce consistency of explanations between researchers and research contexts. Third, we synthesized and validated the findings throughout writing the paper. This was done by a continued interaction between the empirical data and the literature.

\section{Findings}

Our data revealed various dimensions along sensing, seizing, and reconfiguring activities. We first present the results of our descriptive analysis, before interpreting them. Various field data in the form of anecdotal evidence from our data sources (quotations by participants) and existing theories substantiate our findings.

\subsection{Sensing activities}

\subsubsection{Descriptive results}

For our case companies, sensing activities involve five dimensions (see Table 3): (1a) opportunities, (1b) customers, (1c) customer needs, (1d) dynamics of customer needs, and (1e) resource situation. Each dimension entails two options, which organizations explore through a variety of routines.

4.1.1.1. Opportunity dimension. This dimension includes the routines enabling the recognition of internal and external opportunities. Because our case companies operate in emerging and often untapped markets with little competition, these routines (e.g., customer, market foresight) focus on external opportunities related to customers (Halme, Lindeman, \& Linna, 2012). Additionally, attracting customers is vital for creating quick successes throughout the market development. Our case companies also reported routines (e.g., core competence analysis, SWOT (Strength, Weaknesses, Opportunities \& Threats) analysis) that assist managers in analyzing internal competences and later matching them with external opportunities.

4.1.1.2. Customer dimension. This dimension includes direct customers operating the systems and end-customers consuming the water and electricity. Companies reported deploying routines (e.g., utility layers, preferences, and needs for customers) for understanding the needs of direct customers and end-customers. Afterward, they use routines (e.g., system-thinking procedures, causal modeling) for gaining insights into the interrelations among these needs (Neu \& Brown, 2005). Such routines reportedly make organizations aware about the complexity of these interrelations and the difficulties in untangling them. Interviewees used phrases like "spaghetti" or "knotted ball of wool." A typical example is the following statement from ZETA's manager:

When families use electricity, they start with one electric device, but over time they want to own new devices and demand more electricity. We have to increase our electricity supply through additional solar panels, batteries, and, finally, an electricity distribution system.

4.1.1.3. Customer needs dimension. This includes routines for identifying simple and complex needs (e.g., utility layers, typology of customer needs). Needs are considered to be simple if they relate only to single utility layers such as customer productivity, simplicity, convenience, risk, fun and image, and environmental friendliness. Complex needs emerge across various layers. Routines about the typology of customer needs distinguish into functional, problemsolving, and emotional needs.

In addition, case companies reported strengthening routines to gain insights into the factors that affect the complexity of customer needs. Such routines inform managers that a customer need is considered more complex if it is intertwined with other customer needs and if customers have different attributes (e.g., sizes and geographic regions) and therefore differ significantly in terms of how they want to satisfy their underlying needs. ETA's sales manager explained the influence of village size as just such an attribute, as follows:

We target ... villages ranging from 1000 to 4000 end-customers. However, this does not mean that large villages simply demand four times more electricity. Instead, electricity generation, electricity distribution, and peak load management are many times more complex.

Besides the simple and complex customer needs, our data reveal the importance of recognizing the dynamics of customer needs for the sensing activities.

4.1.1.4. Dynamics of customer needs. In this dimension, routines (e.g., scenario predictions, customer foresight, sensitivity analysis) for identifying customer needs allow companies to classify some of them as stable and others as dynamically changing. Our case companies reported utilizing these routines for understanding the degree and nature of change in factors influencing their needs. Dynamic changes result, for example, from responses of customers to new innovations. DELTA's regional manager explained it as follows:

After customers started using solar panels to power electric lights, some were happy with this solution. Other customers immediately want additional solar panels, because they start using mobile phones, radios, fridges, and so on.

Customers adopt new innovations at different rates, thus increasing the diversity among target customers, which in turn creates further dynamics. DELTA argued that.

Customers paying extra for home delivery services gain social status. Neighbors eagerly observe these customers and also want ... status ... leading to a strong growth for such services. 
Table 3

Sensing activities.

Opportunity dimension: balancing internal and external opportunities

\section{Routines External opportunities}

BETA: We focused on recognizing business opportunities and on gaining insights

into customer needs... We used customer and market foresight methods...

GAMMA: It was important to investigate what customers [through customer insight methods] really want and what they need....

DELTA: We analyzed our competitive environment ... and most important gained insights into customer needs and preferences...

\section{Internal opportunities}

BETA: We need to know also our own core competences... We established a mechanism [core competence analysis] to assess whether our competences are valuable. If the competences are valuable, it means that they would match with promising external opportunities...

ETA: Provision of reliable and affordable electricity is our core competence. ... we identified this competence through SWOT-analysis [strengths, weaknesses, opportunities, and threats

\section{Skills $\quad$ Skills for balancing internal and external opportunities}

ALPHA: ... if we want to solve complex customer problems, we need to clearly understand what is strategically important for customers. ... However, we might have focused too much on external opportunities and we did not carefully assess whether these external opportunities actually match our internal competences.

ETA: We matched this competence [core competence] with customer needs to get access to energy... We deliberately developed skills for systematically analyzing internal and external opportunities and for combining them...

Customer dimension: Combining direct customer and end-customer needs

Routines Direct customer needs

BETA: ... we initially focused too much on the direct customer needs and put too little effort into understanding end-customer needs... this delayed our process to become a solution provider...

DELTA: ... but honestly, we initially focused on what our direct customers needed... We asked questions such as "what do our entrepreneurs need to make their water businesses successful?" Questions such as "What expectations do households have on water services?" were too often of second priority.... To answer these questions, we applied methods such as utility layers and categorization of customer needs...

ETA: Causal modeling procedures helped us to understand how end-customer

End-customer needs

BETA: Consumers asked for different modes of transportation to deliver water to households... these needs influence the distribution concept for water ALPHA: Consumers demanding water influence the way how the water treatment equipment is operated... Consumers demanding water influence the way how the water treatment equipment is operated... It was important for us to go beyond the needs of our direct customers and to also understand what end-customers actually need.

GAMMA: We relied on system thinking procedure to link these end-customer needs to the direct customer needs... Skills for combining direct customer and end-customer needs

ALPHA: Consumers demanding water influence the way how the water treatment equipment is operated... It was important for us to go beyond the needs of our direct customers and to also understand what end-customers actually need.

ETA: It took some time until we recognized that it is not enough to identifying only needs of direct customers... we also needed to look into end-customer needs and to combine theses needs... even if the combination of needs looks like a knotted ball of wool.

GAMMA: Skills for anticipating the interrelationships between direct and end-customer needs became important...

Customer need dimension: combining simple and complex needs

Routines Simple customer needs

ALPHA: By structuring needs through the utility layer method... We could easily observe simple need such as consumers demanding $20-1$ jerry cans. ... BETA: ... we understood that without fulfilling the simple needs as well, we would not build sufficient trust to providing complex solutions.
Complex customer needs

ALPHA: ... Even if it was difficult to understand complex needs on the social desire for smaller water volumes (e.g. 1 to $5 \mathrm{l}$ ), we quite much focused on such complex needs.

BETA: As solution providers, we need to solve the complex needs not only the simple ones... We looked for needs emerging in various utility layers... GAMMA: As a solution provider, we solve complex customer needs.... We stuck relatively long to this attitude and just later recognized that it is also appealing for customers to address simple customer needs.... We classified customer needs in functional, problem-solving, and emotional needs

ETA: We target ... villages ranging from 1000 to 4000 end-customers. However, this does not mean that large villages simply demand four times more electricity. Instead, electricity generation, electricity distribution and peak load management is many times more complex...

Skills Skills for combing simple and complex customer needs

DELTA: To navigate through basic and complex customer needs, we need to understand what factors are causing and driving the complexity.

EPSILON: We stuck quite long to targeting only complex needs and forgot a bit to address also the basic needs.... We learned to also focus on simple needs ZETA: Without a sufficient combination of addressing basic and complex needs, we would not be able to succeed as a solution provider.... Skills for prioritizing basic and complex customer needs were important for us...

Dynamics of customer needs: Addressing stable and changing customer needs

Routines Stable customer needs

ALPHA: We could easily observe simple need such as consumers demanding 20-1 jerry cans.

BETA: ... we developed tools to visualize the steady needs of our customers... Such tools were scenario predictions, customer foresight...

DELTA: ... We used a selected procedure for identifying the stable needs of our direct and end-customers.

Changing customer needs

BETA: We were a little bit overambitious and thought that we should prioritize the dynamic customer needs.

GAMMA: After customers started using solar panels to power electric lights, some were happy with this solution. Other customers directly want additional solar panels, because they start using mobile phones, radios, fridges and so on.... Customers paying extra for home delivery services gain social status. Neighbors eagerly observe these customers and want to gain similar status... leading to a strong growth for such services.

EPSILON: We applied a sensitivity analysis to better predict changes in the customer needs..

Skills Skills for addressing stable and changing customer needs

ALPHA: ... when we were still challenged to make our customers satisfied with the provision of safe water in 20-1 jerry cans, we already thought about how to address newly emerging need such as chilled water...The risk of such an overambitious forward-looking approach is that we invest into a cooling system already, before we actually ensure that we make our customer happy...

EPSILON: ... Dynamically changing customer needs are a key priority for solution providers... It was not easy for us to come up with the idea to address both stable and dynamic customer needs.

ETA: Our customers responded differently to our new services... some customers adapted their needs whereas others remained stable... We understood that we need [new skills] to balance both ... targeting stable and dynamic customer needs..

Resource situations: balancing negative and positive conditions 
Table 3 (continued)

Opportunity dimension: balancing internal and external opportunities

\section{Routines Positive resource conditions}

DELTA: ... we did not take advantage sufficiently of positive resource conditions. EPSILON: We used persona methods to gain insights in the resource conditions. ETA: ... rely on mobile payments for electricity usage for reducing transaction costs. Customers can pay small amounts and transfer them frequently, but at the same time we gather important customer information making the co-creation of the solution much more cost efficient.
Negative resource conditions

ALPHA: ... (our) water kiosk entrepreneurs always lack resources. When they make a home delivery, they need to close down the kiosk temporary ... which frustrates other customers ... a family network would mean that family members can operate the kiosk when the entrepreneur is busy.

BETA: We know that entrepreneurs lack the financial resources to become franchisees... we are solution providers and ... have to tackle this issue. GAMMA: In many communities, women manage the entire household, but it remains a cultural taboo to invite our service staff into the house without the husband being present. This limits the provision of ... maintenance services..." DELTA: We developed procedures for analyzing resource conditions among customer groups..

Skills

Skills for balancing negative and positive conditions

ALPHA: We developed skills for better predicting how resource conditions influence the solution provision...

DELTA: We initially focused too much on overcoming negative resource conditions... we did not take advantage sufficiently of positive resource conditions.

EPSILON: Initially, we designed our solution in a way that it addresses the limiting resource condition... later, we tried to understand how we can integrate the positive resource conditions into the value co-creation for our solutions.

Moreover, case companies reported routines assisting them in understanding that the degree and nature of change beyond stable and dynamic needs is a key dimension for the sensing activities.

4.1.1.5. Resource situations. In this dimension, managerial insights into the customer needs help them visualize customers' resource situation necessary for cocreating the solution (Tuli et al., 2007). Routines (e.g., personal methods, customer groups) for visualizing customers' daily lives play a vital role in discovering the resource situation. Born solution providers can face negative or positive resource conditions. A negative resource condition is, of course, a lack of financial resources (London \& Hart, 2004). Other limiting conditions include cultural habits, as GAMMA's sales manager argued:

In many communities, women manage the entire household, but it remains a cultural taboo to invite our service staff into the house without the husband being present. This limits the provision of ... maintenance services.

A positive condition, for example, would be related to reaching out to a network of family members. ALPHA's technical assistant argued that.

[our] water kiosk entrepreneurs always lack resources. When they make a home delivery, they need to close down the kiosk temporary ... which frustrates other customers ... a family network would mean that family members can operate the kiosk when the entrepreneur is busy.

While our descriptive results suggest that each of the five sensing dimensions portrays two options, the interpretation of these results highlights how born solution providers tend to stick to routines associated with one option in each dimension rather than both options.

\subsubsection{Interpretation of results}

The microfoundations pertain not only to the routines reported for these sensing dimensions, but also to individual skills for navigating through both options (see Table 3 ).

4.1.2.1. Skills for balancing internal and external opportunities. Our case companies reported that they tend to focus on the recognition of external opportunities. As ALPHA's manager stated:

$\ldots$ if we want to solve complex customer problems, we need to clearly understand what is strategically important for customers.

This often leads to neglecting the internal opportunities in terms of core competences, which can be utilized for the provision of solutions. For born solution providers, management skills should not only foster the recognition of external opportunities. Managers should be alert about combining external and internal opportunities.

For example, companies should possess skills for systematically analyzing whether the internal competences are valuable, rare, inimitable, and nonsubstitutable, thus achieving competitive advantages that could lead to a combination of internal and external opportunities. The following statement from ZETA's CEO illustrates how managerial alertness to internal competences can facilitate the exploration of external opportunities:

Our managers were alert [that] ... peak load management in the electricity grid is a valuable competence ... since it allows residents to add new electronic devices with a minimum of additional solar panels. ... This competence even gives us an advantage in competing with other solution providers.

4.1.2.2. Skills for anticipating interrelationships between direct and endcustomer needs. A similar observation emerged for gaining insights into direct and end-customer needs. Companies tend to focus only on their direct customers, whom they believe provide insights into endcustomer needs (Kindström, 2010). Less attention is placed on independently gaining insights into the needs, preferences, and habits of end-customers.

Without exploring end-customer needs, it is difficult to accurately predict the factors influencing the complexity and dynamics of customer needs. Skills for gaining insights into the customers should be applied to direct and end-customers. Furthermore, skills for anticipating the interrelationships among these needs should counteract the tendency to stick to direct customer needs.

4.1.2.3. Skills for addressing simple and complex customer needs. A simple need that ALPHA's end-consumers demand, 20-1 jerry cans, is easily observable. A more complex need, when end-customers with a lower income level have a desire for smaller water volumes (e.g., one to five liters) is more difficult to observe. It could be rational to assume that born solution providers target only simple needs, because they are easier to observe. However, our case companies reported often being too ambitious in trying to address the complex needs directly. Even if complex needs are difficult to observe, companies focus only on them. They overlook the simple needs, which would in fact enable quick wins through improving customer satisfaction, and which are compelling for customers.

For example, GAMMA put considerable effort into providing solutions for distributing small water volumes but failed to establish a sufficient basic water distribution system for 20-1 jerry cans. To avoid such stickiness to complex customer needs, organizations should place 
similar priorities on simple and complex needs. Additionally, managers should recognize the importance of quick wins by satisfying simple needs. Again, skills for addressing simple and complex customer needs are a key success factor for born solution providers.

4.1.2.4. Addressing stable and dynamic customer needs. Similarly, we observed that born solution providers might fail because they believe that the success of providing solutions depends only on addressing rapidly changing customer needs. Addressing these needs is seen as vital for achieving the "valuable" criteria for customers and making the solution inimitable for competitors. As GAMMA's CEO suggested:

...when we were still challenged to make our customers satisfied with the provision of safe water in 20-1 jerry cans, we already thought about how to address newly emerging needs such as chilled water ... The risk of such [a] ... forward-looking approach is that we invest in a cooling system before we actually ensure that we ... make our customers happy.

To succeed, born solution providers develop skills for addressing both stable and changing customer needs.

4.1.2.5. Predicting negative and positive resource conditions. By envisioning solutions to customer problems, born solution providers naturally prioritize dealing with negative resource conditions. As ZETA's sales manager noted:

We want to overcome the conditions confronting the village inhabitants, which prevent them from access to reliable energy.

Similarly, BETA's CEO argued, "We know that entrepreneurs lack the financial resources to become franchisees... we are solution providers and ... have to tackle this issue."

Visualizing resource conditions in a way that only negative conditions are recognized strengthens the tendency to overemphasize complex and dynamic customer needs, leaving behind the simple and stable ones, which could enable quick wins. An excessively strong focus on negative resource conditions can make the entire solution unaffordable for customers in emerging markets.

Therefore, born solution providers should possess skills for acknowledging the negative resource conditions and predicting how they can take advantage of positive resource conditions for the co-creation of the solution. For example, predicting the widespread use of mobile payment systems in emerging markets enabled ETA to utilize them for payments for electricity usage as a means of reducing transaction costs. ETA anticipated going even further in gathering important customer information through mobile communication technologies, which makes the co-creation of the solution much more cost-efficient. Accordingly, born solution providers need to develop skills for addressing both negative and positive resource conditions. Table 3 summarizes the key empirical evidence for the sensing dimensions.

\subsection{Seizing activities}

\subsubsection{Descriptive results}

Seizing includes the following dimensions (see Table 4): (2a) scope of the offering, (2b) solution conceptualization, (2c) individualization, and (2d) customer segments. Again, each dimension contains two options.

4.2.1.1. Scope of the offering. This dimension entails routines (e.g., solution innovation processes, stage-gate models) leading to either a narrow or broad scope of products and services. Narrow means that the solution innovation procedures guide companies toward specializing in a few products and services, which address only the most important customer needs. Such a specialization makes the solution easily repeatable, leading to quick cost reductions (Galbraith, 2002). A broad solution scope means that customer needs are solved more comprehensively, which is, of course, more attractive for customers. However, repeating such a broad solution from one customer to the next is challenging, because the entire solution has to be repeated (Davies \& Brady, 2000).

Solution elements, which are often repeated from one customer to the next, include pay-per-use services. Independent from the scope of the offerings, companies deploy routines (e.g., customer value quantification, lead customer procedures, pay-per-use fees) that make payper-use payment structures viable (see Table 2). These routines are interrelated with the decision on whether product and service costs are included in the pay-per-use fee or charged separately.

4.2.1.2. Solution conceptualization. This dimension entails routines (e.g., solution configurators, value-based pricings) for pricing and sales of the main solution-bundling all products and services and selling the package through a pay-per-use payment structure or unbundling them and charging separately (Den Hertog et al., 2010). Value-based pricing assists our case companies in calculating the payper-use fee, in terms of how much customers are able to pay for a kilowatt hour of electricity and a cubic meter of water. Bundling too many solution elements can systematically raise prices, and customers may no longer recognize these higher prices as justified in terms of the value of the solutions (Cusumano et al., 2015).

Thus, it is important that managers apply routines for thinking carefully and actively about unbundling some solution elements and charging for them separately (Gebauer, Saul, Haldimann, \& Gustafsson, 2017). For example, DELTA unbundles all solution elements that are relevant, once customers operate the systems. DELTA's manager argued that.

... once our customers operate the water treatment equipment ... they make money. Customers are willing to ... pay for consulting services ... because they help customers to expand their business.

4.2.1.3. Individualization dimension. Once companies have bundled or unbundled solution elements, they should utilize routines (e.g., modularization, process blueprinting) for determining the degree of individualization of the solutions in terms of standardizing and customizing solutions and/or solution elements (Neu \& Brown, 2005). ZETA's sales manager described this decision as follows:

Once we decided to provide financial services for electric devices, we needed to decide whether we should standardize our payback schemes ... or customize them.

A smart balance of standardized and customized solution elements enables our case companies to target single and/or multiple customer segments.

4.2.1.4. Customer segmentation. If companies customize solutions, they are able to target multiple customer segments with heterogeneous needs (Neu \& Brown, 2005). Targeting multiple segments requires routines for adapting the solution to the specific needs of each segment as well as routines for deciding whether certain solution elements are standardized across multiple segments or customized for each segment or even each individual customer. Targeting multiple segments conforms to growth objectives that are less dependent on a single customer segment. BETA's sales manager explained this rationale as follows:

To grow quickly, ... it is a good idea to target at least public utilities, private entrepreneurs, and village communities. ... When we customize our safe drinking water solutions, we can succeed in each of the three customer segments.

Although targeting multiple segments can create certain benefits, companies have utilized routines to reflect on whether these benefits exceed the costs of customizing solutions to the specific needs of these 
Table 4

Anecdotal evidences on seizing activities.

Scope of the offering: Narrow and/or broad scope

\section{Routines Narrow scope}

GAMMA: ... However, operating the systems is costly. It would be more cost efficient to transfer system operation to our customers, while we would narrow down our solution to trouble-shooting services.

EPSILON: If we want to be more cost competitive, it is necessary for us to narrow down our solution... We used a customer value quantification methods to reveal our costs...

ETA: We implemented a solution innovation process... to determine the scope of the solution..

Skills Skills for navigating through a narrow and broad scope of solution offering

ALPHA: We developed skills for determining whether a narrow or broad scope is most suitable...

BETA: Naturally, we thought that broadening our scope of the solution is the best way to become a trusted solution provider... Cost reasons motivated us to better balance a too narrow and too broad scope of the solution offering...

DELTA: Carefully considering the two options of having a narrow and of having a broad scope of the solution became a key success factor for us...

ETA: If we want to solve complex customer needs, it is natural that our solution becomes quite broad... But we need to be careful and always consider ways to narrow down our solution and to specialize on certain solution elements...

Solution conceptualization: Bundling and unbundling solution elements

Routines Bundling

ALPHA: Solution configurators support us out bundling decisions...

BETA: ... we initially focused too much on the direct customer needs and put too

little effort into understanding end-customer needs... this delayed our process to

become a solution provider...

DELTA: ... but honestly, we initially focused on what our direct customers

needed... We asked questions such as "what do our entrepreneurs need to make

their water businesses successful?" Questions such as "What expectations do

households have on water services?" were too often of second priority.

\section{Broad scope}

ALPHA: Since we initially thought that we should target complex and dynamic customer needs, it was obvious for us that we broadened our scope of the solution... much later when we recognized our costs, we considered to narrow down our solution.

BETA: Our stage-gate model suggested to offer a broad scope of solution elements...

GAMMA: ... as solution providers, we need to support customers as much as possible. ... we relied on lead customer procedures to determine the scope of our solutions...

EPSILON: Estimating the pay-per-use fee was an important indicator for the scope of the solution offering
Unbunding

ALPHA: Consumers demanding water influence the way how the water treatment equipment is operated... Consumers demanding water influence the way how the water treatment equipment is operated... It was important for us to go beyond the needs of our direct customers and to also understand what end-customers actually need.

BETA: Consumers asked for different modes of transportation to deliver water to households... these needs influence the distribution concept for water...

GAMMA: Value-based pricing methods were very helpful for understanding if we should unbundle solution elements..

Skills $\quad$ Skills for deciding about bundling and unbundling of products and services

ALPHA: Consumers demanding water influence the way how the water treatment equipment is operated... It was important for us to go beyond the needs of our direct customers and to also understand what end-customers actually need.

BETA: We introduced skills for balancing bundling and unbundling of the solution elements... We recognized more strongly revenue opportunities....

Individualization dimension: standardization and customization

Routines Standardization

ALPHA: To make our solutions affordable, we tried to standardize our services... We used a blueprinting procedure for guiding the standardization of the solution elements

BETA: Customers are not willing to be extra for customizing our solutions to their specific needs... Therefore, we aimed for standardizing our solution as much as possible...

GAMMA: Standardizing our solutions help us to be very affordable... however, being very affordable is not the only purchasing criteria for customers...

DELTA: The limited financial resources of customers in emerging markets restricts higher prices... We assumed that the one-size-fits-all approach to providing solutions... is most beneficial to us.

ETA: Once we decided to provide financial services for electric devices, we needed to decide whether we should standardize our payback schemes ... or customize them.

Skills Skills for balancing standardization and customization

ALPHA: We needed skills of standardizing and customizing our solutions..

BETA: Our managers became increasingly alert that we need to go beyond a one-size fit all approach...

ETA: Once we decided to provide financial services for electric devices, we needed to decide whether we should standardize our payback schemes .... or customize them. ZETA: Standardization and customization... both are key to success for being a solution provider.

Customer segmentation: Single and multiple segments

Routines Single customer segment

BETA: To gain momentum in the market development, it was better to focus on a single market segment...

GAMMA: ... we recognized that providing solutions was truly unique for each of the segments... uniqueness made it difficult for our sales agents to advance their solution competences... Thus, we refocused on the village segment with various different village sizes... This segment is large enough for rapid growth. ... Village sizes lead to heterogeneous needs and require customization..."

Customization

GAMMA: ... Customers want to be ensured that the solution fits their individual needs...

DELTA: ... Customizing might be costly in the initial sales phase... but if we do it right, it can increase customer satisfaction and attract more customers over time. ETA: ... Modularization procedure allowed us to customize the solutions... Our solution configurator visualized the customized and standardized solution elements..

\section{Multiple customer segments}

ALPHA: Initially, we thought that it is best to target multiple segments... however, we struggled quite a lot... to cover the various requirements of these multiple segments..

BETA: Targeting multiple segments from the beginning was much too complex for us...

ETA: To grow quickly, ... it is a good idea to target at least public utilities, private entrepreneurs, and village communities... When we customize our safe drinking water solutions, we can succeed in each of the three customer segments.

Skills Skills for timing the sequence of entering single and multiple customer segments

ALPHA: Market planning skills were important for developing our customer segment strategy

DELTA: After we had provided safe water solutions to nearly 450 villages, we started to target the new segment of public utilities. To do so, we create market and strategic planning skills...

EPSILON: Selecting one single segment for the early market development and ... diversifying later into multiple segments became an important trigger for us to generate attractive growth rates...

ZETA: Focusing on a single segment first ... and carefully extending into multiple segments later, was important for us...Here, we relied on our business development competences... 
customer segments. Companies use decision-support methods for comparing the costs and benefits of targeting multiple segments versus single segments.

\subsubsection{Interpretation of results}

Again, our case companies need to develop individual skills supporting them in navigating through the options of the seizing dimensions (see Table 4).

4.2.2.1. Skills for balancing narrow and broad scope of solution. As suggested by a DELTA sales manager, case companies favor a relatively broad offering: "[as] solution providers, we need to support customers as much as possible." However, as a side effect, such a broad offering is less repeatable, and thus it jeopardizes the firm's profitability (Davies \& Brady, 2000). Without specializing in just a few solution elements, companies cannot benefit fully from cost reductions. DELTA's sales manager explained it as follows:

... a narrow solution could be sold to many customers ... quickly improving costs through a steep learning curve. ... [Alternatively,] ... providing a broad solution takes time ... [so that the] learning curve and economies of scale are limited.

Besides limiting cost improvements, a broad solution scope can systematically raise prices above the level that customers regard as reasonable. As the experience of GAMMA suggests, companies should actively narrow down the solutions:

Initially, we thought that not operating water treatment systems ourselves could become an Achilles heel for our solution.... However, operating the systems is costly. It would be more cost efficient to hand over the system operation to our customers, and we would narrow down our solution to troubleshooting services.

As these examples suggest, skills determining the scope of the solutions should ensure that the solutions are not becoming too broad and costly, but remain attractive and affordable for customers. Born solution providers thus actively explore both a narrow and a broad scope of the solution. The scope of the solution informs the decision about whether to bundle or unbundle the solution conceptualization.

4.2.2.2. Skills for deciding about bundling and unbundling of products and services. Our case companies reported that they focus on bundling and often neglect the unbundling of solution elements. Yet such unbundling seems rational, because it avoids the high costs of solutions and offers new revenue opportunities (Den Hertog et al., 2010; Storbacka et al., 2013). Nevertheless, companies may favor the bundling of solution elements. As DELTA's manager argued, the company is often convinced that.

our customers ... will not pay for additional services. ... All products and services should be included in the pay-per-use fee, because they help to augment our solution offering.

However, born solution providers need to actively create skills for balancing the bundling and unbundling of solution elements. Born solution providers should introduce competences for unbundling those services, which enable customers to generate additional revenue. In addition, managers should recognize that such additional revenue means that customers have sufficient financial resources to pay for these additional services.

4.2.2.3. Skills for balancing standardizing and customizing solution elements. Customizing facilitates adapting the solution to individual customer needs, which increases customer value. Such value motivates customers to pay higher prices, but our case companies reported being hesitant as to whether these higher prices are feasible in emerging markets. Thus, they favor a standardization of the solution. DELTA's head of sales phrased it as follows:
The limited financial resources of customers in emerging markets restricts higher prices. ... We assumed that the one-size-fits-all approach to providing solutions ... is best for us.

To become successful, born solution providers clearly need to go beyond the one-size-fits-all approach. DELTA's head of sales substantiated the argument as follows:

We cannot succeed with a one-size-fits-all solution. ... It requires employees who are open to that idea. ... Customizing might be costly in the initial sales phase ... but if we do it right, it can increase customer satisfaction and attract more customers over time.

Born solution providers need skills to assist them in customizing their solutions to address more heterogeneous customer needs. Such skills allow them to carefully balance options, such as standardization and customization.

4.2.2.4. Skills for timing the entry into single and multiple customer segments. Focusing on single customer segments is beneficial in the early stage of being a born solution provider. GAMMA's CEO argued in the following way:

We recognized that solutions were truly unique for each of the segments ... uniqueness made it difficult ... to advance [our] solution competences. ... Thus, we refocused on the village segment.

At a later stage, born solution providers should develop market planning skills for moving from single segments toward diversifying into multiple segments. DELTA's CEO expressed it as follows:

After we had provided safe water solutions to nearly 450 villages, [market planning skills suggested that] we started to target the new segment of public utilities.

While the managerial ambition of born solution providers to grow quickly favors multiple customer segments, market and strategic planning skills should ensure an accurate timing of the market entry sequence from single to multiple customer segments.

\subsection{Reconfiguring activities}

\subsubsection{Descriptive results}

The reconfiguration follows these seizing activities. Our findings reveal two relevant dimensions (see Table 5): (3a) organizational resources and (3b) solution modifications.

4.3.1.1. Organizational resources. Organizational resources can be optimized or expanded. Naturally, achieving growth during market development requires routines (e.g., multiunit approach for growing the organization, resource planning procedures) that guide the continuous expansion of their organizational resources (Den Hertog et al., 2010). For example, GAMMA's CEO explained that.

Each team can support about 20 customers. ... If we reached more than 20 customers in one region, we started to build another team ... continuously expanding our organization... through the replication of organizational units....

In addition to extending the organizational resources, our case companies reported routines (e.g., continuous improvement programs, critical incident-mapping of frequent and relevant problems) for optimizing their organizational processes. GAMMA's CEO explained further:

We estimated annual costs for maintaining the equipment to be approximately USD 2600 .... This was more than $50 \%$ of our total equipment costs. ... We introduced initiatives [cost optimization activities] ... to reduce our maintenance costs down to USD 340.

Besides reconfiguring the organizational resources, our data reveal a need to modify the solutions themselves. 
Table 5

Reconfiguring activities.

Organizational resources: optimizing and extending the organization

Routines Optimizing the organization

ALPHA: We used a continuous improvement program for optimting our organizations..

GAMMA: ... we estimated annual costs for maintaining the equipment to be approximately USD $2600 \ldots$ This was more than $50 \%$ of our total equipment costs ... We introduced initiatives ... to reduce our maintenance costs down to USD $340 \ldots . .$. [instead of 20 customers] ... our solution teams ... can [now] serve up to 90 customers..
Expanding the organization

ALPHA: We focused more on expanding our organization rather than optimizing our organization...

BETA: Expanding our organization was our first priority... much later we also prioritized optimizing the organization...

GAMMA: Each team can support about 20 customers ... it is difficult to predict this number, but we thought that this is a good estimate for guiding our organizational extension. If we reached more than 20 customers in one region, we started to build another team...continuously expanding our organization... EPSILON: We used a multiunit replication approach to expand our organization.. ETA: In the market development, expanding the organization was our first priority...

Skills $\quad$ Skills for balancing the optimization and expansion of the organization ALPHA: Management skills for balancing growth and optimization ... were very important... DELTA: Careful balancing the optimization and expansion of the organization was a key enabler for surviving the early market development... EPSIPLON: Expansion and optimization are two sides of the same coin... We needed both to be successful... ETA: In the market development, expanding the organization was our first priority... however... without optimizing the organization at the same time, we would not have been successful.

ZETA: An intelligent combination of expansion and optimization is a key factor for the market development...

Solution offerings: freezing and revising the offering

Routines Freezing the offering

ALPHA: Once we defined our solution for providing safe and affordable water... we thought that it is best to freeze the solution...

BETA: Process blueprinting helped us to freeze our offerings... GAMMA: To be cost competitive, we tended to freeze our solution rather quickly... DELTA: We used modularization procedures to freeze our solution offerings... ESPILON: Remote services led to a certain revision of the solution.... However, we were not completely convinced that we should do so... since we specified our solution already..

\section{Revising the offering}

ALPHA: Solution configurators ...supported us in the revision of the offering BETA: We revised our solution through the introduction of self-diagnosis

systems... Our self-diagnosis system supports customers in performing short daily inspections, cleaning, timely backwashing, lubricating and small adjustments.

Our service technicians concentrate on more complex failures, thereby saving on service costs.

DELTA: Our initial solution included a [single] water treatment system for USD

5000 ... Later, we revised the solution to include a water treatment system, water distribution points [water ATMs], and water piping systems. Costs nearly tripled, but revenue was even six times higher...

Skills

Skills for balancing freezing and revising the offering

ETA: We were convinced that freezing our solution was a key to reduce our costs... we initially failed to recognize that revising the solution is also very beneficial... ZETA: A careful balance between keeping the initial solution and revising the solution was highly important...

4.3.1.2. Solution modifications. When it comes to solution modifications, companies reported routines (process blueprinting, solution configurators, modularization, customization and standardization procedures) for either freezing or revising the solutions. Solutions are easier to optimize if companies have frozen their solution offering, in the sense that they have specified the elements. It is easier to improve the delivery process for clearly defined solutions. Revisions, for example, can mean eliminating, substituting, and extending some solution elements. For example, when BETA introduced self-diagnosis elements, training services for maintenance activities became obsolete. The self-diagnosis system now assists customers in performing maintenance procedures. Other companies have revised the solutions after introducing remote monitoring elements (see Table 5).

Again, skills for navigating through these options became a key success factor for born solution providers.

\subsubsection{Interpretation of results}

4.3.2.1. Skills for navigating through the optimization and expansion of organizational resources. Our case companies are afraid of having insufficient resources to ensure solution outputs (e.g., quality, performance, costs), which remain compelling for customers. Without such an output, companies are concerned as to whether they can achieve the necessary growth. Thus, organizations deploy routines for expanding the organizational resources far in advance.

As GAMMA's CEO argued, "We never really thought about how we could optimize our entire organization." Born solution providers need skills to balance organizational expansion and optimization. They should develop skills for making appropriate decisions for growing the organization quickly during market development and for continuously optimizing the entire organization to minimize solution costs, making them attractive for customers. GAMMA's CEO continued the argument by saying that "[instead of 20 customers] ... our solution teams ... can [now] serve up to 90 customers." Our case organizations reported deploying dedicated routines for expanding and optimizing the organization. In addition, they emphasize management skills that balance growth and optimization in the organization.

4.3.2.2. Skills for deciding about freezing and revising solutions. Similarly, organizations stick to routines for freezing the existing solution offering. Such routines make the solution easier to repeat and strengthen the skills for reducing costs. However, this restricts possible improvements that would be possible through revising the solution offerings.

Continuous revisions of solution elements are necessary because the solutions, including product design and functionality, as well as service elements, are still in a state of flux (Cusumano et al., 2015). Managers should develop skills for recognizing that the revision of the solution offering is not only about cost reduction, but also about possibly raising customer satisfaction. As DELTA's sales manager stated:

Our initial solution included a [single] water treatment system for USD 5000. ... Later, we revised the solution to include a water treatment system, water distribution points [water ATMs], and water piping systems. Costs nearly tripled, but revenue was even six times higher.

Thus, born solution providers deploy skills for addressing both freezing and revising as options of the solution dimension.

\subsection{Learning activities}

The individual skills necessary for navigating through the various options underlying sensing, seizing, and reconfiguring activities do not emerge automatically. Instead, we observed that skills emerge through 
learning activities in terms of single-loop and double-loop learning, as higher-order capabilities (Den Hertog et al., 2010; Zollo \& Winter, 2002). The former occurs when companies merely modify their skills according to the objectives and outcomes. ALPHA's local entrepreneur described such single-loop learning for skills for balancing standardizing and customizing solution elements and for bundling and unbundling of products and services:

We were quite convinced that we can achieve financial targets ... but sales remained below our expectations. ... We improved our marketing strategy [skills], distribution systems. ... Things improved.

Double-loop learning means that companies question their mental models and the objectives. ALPHA's CEO illustrated such double-loop learning for skills on balancing a narrow and broad scope of solution offerings:

We critically questioned our objective and mental model of relying only on selling water ... we decided to move to selling water and energy services ... finally enabling us to achieve our financial target.

Interestingly, relying only on single-loop or double-loop learning is not sufficient for developing the necessary individual skills. For example, only when ALPHA's firm combined single-loop and double-loop learning was it able to develop the necessary individual skills for becoming a born solution provider. Only when our case companies carefully combined the single-loop and double-loop learning could they succeed as born solution providers.

\section{Discussion}

\subsection{Theoretical and empirical implications}

Our findings on born solution providers have several implications. Empirically, through our focus on companies in the market development phase and emerging markets, we depart from the previous research focus on established companies in industrialized markets (Kowalkowski et al., 2017; Luoto et al., 2016).

Theoretically, we scrutinized the microfoundation of dynamic capabilities (Teece, 2007) for becoming born solution providers. This microfoundation provides detailed empirical evidence on routines and skills guiding the sensing, seizing, and reconfiguring activities. Our findings on learning activities are in line with the argument of Den Hertog et al. (2010) on deliberate learning for modifying and improving the service innovation process. Deliberate learning in terms of singleloop and double-loop processes are higher-order capabilities influencing the emergence of the skills for navigating through the various options for the dimensions underlying the sensing, seizing, and reconfiguring activities (Eisenhardt \& Martin, 2000; Zollo \& Winter, 2002).

This microfoundation advances the existing research in four ways. First, this foundation contains 10 dimensions, each of which has two options. Companies deploy routines for exploring these options and skills for navigating through them, so as to alter operational capabilities and enhance performance. Our microfoundation might be limited, because it overlaps with operational capabilities. Nevertheless, our findings can be substantiated with previous dynamic capability discussions.

Second, our 10 dimensions advance previous capability descriptions for providing solutions (e.g., Davies et al., 2006; Galbraith, 2002; Tuli et al., 2007; Ulaga \& Reinartz, 2011). Our insights into options covering a broad scope of the offering, customization, complex customer needs, and rapidly changing customer needs are in line with the argument that providing solutions requires capabilities to become more customercentric and to entail customized solutions (Galbraith, 2002). However, our findings also suggest that sensing only external opportunities, as advocated by the notion of market-focused learning (e.g., anticipating market developments and customer requirements) (Weerawardena \&
O'Cass, 2004), is not sufficient for born solution providers. Instead, born solution providers have to systematically assess their own competences to gain an understanding of internal opportunities, which are later matched with external opportunities.

Our individualization dimension with the options of standardization and customization confirms arguments that companies need to focus simultaneously on commercialization and industrialization. Industrialization (i.e., standardization) has often been neglected in the literature, because the emphasis has been on revenue generation rather than cost-efficiency (Kowalkowski, Windahl, Kindström, \& Gebauer, 2015; Storbacka, 2011).

Our sensing dimensions offer guidance for gaining insights into customer requirements. For example, gaining insights into the needs of direct and end-customers is similar to the notion of managing relational processes with customers (Kindström, 2010; Tuli et al., 2007).

Our seizing dimensions advance the notion that firms will not know precisely, a priori, what solution will be successful in the market; thus, an evolutionary perspective suggests a need for tentative steps of trial and error. These steps are about balancing the options of the relevant dimensions. If companies narrow down the scope of the solution offering, it may be more likely to bundle all products and services into the narrow solution. Within this bundle, companies can easily start to standardize the solution elements. As a downside, such a relatively narrow, bundled, and standardized solution might be compelling only for a single customer segment.

The options of optimizing and expanding, with respect to the dimension of organizing solutions, advance the capability description for scaling organizations (Den Hertog et al., 2010). Born solution providers are not only challenged to introduce solutions on a large scale in a uniform way (Lyons et al., 2007) and to extend the organizational network (Windahl \& Lakemond, 2006), but must also optimize and expand the organization simultaneously.

Compared to existing literature considering technology exploration as a sensing activity (Kindström et al., 2013), our findings suggest that technology options (e.g., self-service and remote monitoring technologies) play a vital role in reconfiguration activities, because they enable companies to revise their solutions.

Third, we identify the relevant routines underlying these dimensions. We could observe that companies often stick to routines for certain options of the dimensions, rather than addressing both options (e.g., routines leading standardization (one-size-fits-all) rather than utilizing routines on customization). That means that not only existing operational capabilities are "sticky" and difficult to modify. The same argument can be applied to organizational routines and individual skills, which also embody a degree of inertia that does not readily permit change (Ceci \& Masini, 2011). Such "stickiness" can limit moving toward solutions, because it inhibits reasonable alignment among the options for the dimensions. For example, if companies stick to addressing only limiting resource conditions, it would restrict the way these companies sense the dynamics and degree of complexity inherent in customer needs. Such an argument strengthens the research applying contingency theory. We could also identify the necessary skills for balancing the various options of dimensions. These skills extend Galbraith's (2002) idea that convergent thinking enables companies to provide solutions in a way that is best for customers.

Fourth, our findings can be used to develop testable propositions, which can guide quantitative research on the influence of dynamic capabilities regarding altering the operational capabilities necessary to provide solutions. Such research could yield normative statements concerning optimal configurations of dynamic capabilities for becoming born solution providers. In this context, our microfoundation can guide the operationalization of constructs for future empirical research. Some scales and construct descriptions already exist for dynamic capabilities. For example, seizing capabilities have previously been operationalized as a single construct with multiple items (Wilden, Gudergan, Nielsen, \& Lings, 2013). Our findings suggest that dynamic 
capabilities should be operationalized as a higher-order construct, including three first-order constructs (e.g., sensing, seizing, reconfiguring). The operationalization of the first-order constructs could be derived from the routines and skills comprising our microfoundations.

Overall, this microfoundation supplements previous research on management practices, individual skills, and dynamic capabilities for providing solutions. It addition, it supplements previous arguments that solution provision requires multiple (operational) capabilities. Providing solutions also requires multiple dynamic capabilities (routines and skills) as well as higher-order learning capabilities.

\subsection{Practical implications}

Companies attempting to become born solution providers should visualize the detailed facets of the routines and skills underlying our 10 dimensions. Practitioners should assess the current strengths and weaknesses according to the fundamental options of sensing, seizing, reconfiguring, and learning activities. Based on this assessment, companies can make strategic decisions for capability development.

Practitioners should understand that born solution providers can fail if they only gain insights into complex customer needs, rapidly changing needs, and so on. There is a tendency to stick to some of these options. Practitioners should balance the opposing options for all dimensions. For example, managers should also gain an understanding of simple and stable customer needs. Targeting these needs can generate quick gains in customer satisfaction, which enhance the credibility, reputation, and trust necessary to succeed as a born solution provider.

Practitioners should explore innovative solutions through tentative trial-and-error steps along the dimensions comprising the scope of the offering, solution conceptualization, individualization, and customer segments. In addition, tentative steps mean that practitioners should converge their thinking along the options for each dimension, in order to provide solutions in a manner that is best for their customers. Finally, practitioners need to understand that focusing only on single-loop or double-loop learning can be counterproductive. A combination of both types is necessary.

\subsection{Limitations and further research directions}

Inevitably, our qualitative study has its limitations, although some offer promising directions for future research. A logical next step would be an application of our microfoundation of dynamic capabilities to born solution providers in other industries, which would offer a noteworthy contrast to our empirical context. This could reveal new insights and show which dimensions, options, routines, and skills could be generalizable. It would also be interesting to apply our dynamic capabilities to product firms in the growth or maturity phase. Future research could investigate whether our capabilities also facilitate a move from products to solutions in these phases. Finally, future studies could concentrate on single activities with respect to sensing, seizing, and reconfiguring, as well as learning activities. Although these limitations should be kept in mind, we are confident that our findings provide useful new insights for academics and practitioners alike.

\section{References}

Ambrosini, V., Bowman, C., \& Collier, N. (2009). Dynamic capabilities: An exploration of how firms renew their resource base. British Journal of Management, 20(s1), S9-S24.

Ceci, F., \& Masini, A. (2011). Balancing specialized and generic capabilities in the provision of integrated solutions. Industrial and Corporate Change, 20(1), 91-131.

Ceci, F., \& Prencipe, A. (2008). Configuring capabilities for integrated solutions: Evidence from the IT sector. Industry and Innovation, 15(3), 277-296.

Chandler, A. D. (1990). Scale and Scope: The Dynamics of Industrial Capitalism. Cambridge, MA: Belknap Press of Harvard Univ. Press.

Cohen, M. A., Agrawal, N., \& Agrawal, V. (2006). Winning in the aftermarket. Harvard Business Review, 84(5), 129.

Cusumano, M. A., Kahl, S. J., \& Suarez, F. F. (2015). Services, industry evolution, and the competitive strategies of product firms. Strategic Management Journal, 36(4), $559-575$.

Davies, A. (2004). Moving base into high-value integrated solutions: A value stream approach. Industrial and Corporate Change, 13(5), 727-756.

Davies, A., \& Brady, T. (2000). Organisational capabilities and learning in complex product systems: Towards repeatable solutions. Research Policy, 29(7), 931-953.

Davies, A., Brady, T., \& Hobday, M. (2006). Charting a path toward integrated solutions. MIT Sloan Management Review, 47(3), 39.

Davies, A., Brady, T., \& Hobday, M. (2007). Organizing for solutions: Systems seller vs. systems integrator. Industrial Marketing Management, 36(2), 183-193.

Den Hertog, P., van der Aa, W., \& de Jong, M. W. (2010). Capabilities for managing service innovation: Towards a conceptual framework. Journal of Service Management, 21(4), 490-514.

Eggert, A., Hogreve, J., Ulaga, W., \& Muenkhoff, E. (2014). Revenue and profit implications of industrial service strategies. Journal of Service Research, 17(1), 23-39.

Eisenhardt, K. M. (1989). Building theories from case study research. Academy of Management Review, 14(4), 532-550.

Eisenhardt, K. M., \& Martin, J. A. (2000). Dynamic capabilities: What are they? Strategic Management Journal, 21(10/11), 1105-1121.

Evanschitzky, H., van Wangenheim, F., \& Woisetschläger, D. (2011). Service \& solution innovation: Overview and research agenda. Industrial Marketing Management, 40(5), 657-660.

Fang, E., Palmatier, R. W., \& Steenkamp, J. B. E. (2008). Effect of service transition strategies on firm value. Journal of Marketing, 72(5), 1-14.

Felin, T., \& Foss, N. J. (2009). Organizational routines and capabilities: Historical drift and a course-correction toward microfoundations. Scandinavian Journal of Management, 25(2), 157-167.

Fischer, T., Gebauer, H., Gregory, M., Ren, G., \& Fleisch, E. (2010). Exploitation or exploration in service business development? Insights from a dynamic capabilities perspective. Journal of Service Management, 21(5), 591-624.

Forkmann, S., Ramos, C., Henneberg, S. C., \& Naudé, P. (2017). Understanding the service infusion process as a business model reconfiguration. Industrial Marketing Management, 60, 151-166.

Galbraith, J. R. (2002). Organizing to deliver solutions. Organizational Dynamics, 31(2), 194-207.

Gebauer, H. (2011). Exploring the contribution of management innovation to the evolution of dynamic capabilities. Industrial Marketing Management, 40(8), 1238-1250.

Gebauer, H., Saul, C. J., Haldimann, M., \& Gustafsson, A. (2017). Organizational capabilities for pay-per-use services in product-oriented companies. International Journal of Production Economics, 192, 157-168.

Glaser, B. G., \& Strauss, A. L. (2009). The discovery of grounded theory: Strategies for qualitative research. Transaction Publishers.

Halme, M., Lindeman, S., \& Linna, P. (2012). Innovation for inclusive business: Intrapreneurial bricolage in multinational corporations. Journal of Management Studies, 49(4), 743-784.

Helfat, C. E., Finkelstein, S., Mitchell, W., Peteraf, M. A., Singh, H., Teece, D. J., \& Winter, S. G. (2007). Dynamic capabilities: Understanding strategic chance in organizations. Oxford: Blackwell.

Helfat, C. E., \& Peteraf, M. A. (2009). Understanding dynamic capabilities: Progress along a developmental path. Strategic Organization, 7(1), 91-102.

Kindström, D. (2010). Towards a service-based business model-key aspects for future competitive advantage. European Management Journal, 28(6), 479-490.

Kindström, D., Kowalkowski, C., \& Sandberg, E. (2013). Enabling service innovation: A dynamic capabilities approach. Journal of Business Research, 66(8), 1063-1073.

Kotler, P., \& Armstrong, G. (2010). Principles of marketing. Pearson Education.

Kowalkowski, C., Gebauer, H., \& Oliva, R. (2017). Service growth in product firms: Past, present, and future. Industrial Marketing Management, 60(1), 82-88.

Kowalkowski, C., Windahl, C., Kindström, D., \& Gebauer, H. (2015). What service transition? Rethinking established assumptions about manufacturers' service-led growth strategies. Industrial Marketing Management, 45(1), 59-69.

Kuhn, T. S. (1970). Logic of discovery or psychology of research. Criticism and the Growth of Knowledge, 1-23.

Lenka, S., Parida, V., Sjödin, D. R., \& Wincent, J. (2017). Exploring the microfoundations of servitization: How individual actions overcome organizational resistance. Journal of Business Research. http://dx.doi.org/10.1016/j.jbusres.2017.11.021.

Leonard-Barton, D. (1992). Core capabilities and core rigidities: A paradox in managing new product development. Strategic Management Journal, 13(S1), 111-125.

Lincoln, Y. S., \& Guba, E. G. (1985). Naturalistic inquiry. Beverly Hills: CA Sage.

London, T., \& Hart, S. L. (2004). Reinventing strategies for emerging markets: Beyond the transnational model. Journal of International Business Studies, 35(5), 350-370.

Luoto, S., Brax, S. A., \& Kohtamäki, M. (2016). Critical meta-analysis of servitization research: Constructing a model-narrative to reveal paradigmatic assumptions. Industrial Marketing Management, 60(1), 89-100.

Lyons, R. K., Chatman, J. A., \& Joyce, C. K. (2007). Innovation in services: Corporate culture and investment banking. California Management Review, 50(1), 174-191.

March, J. G. (1991). Exploration and exploitation in organizational learning. Organization Science, 2(1), 71-78.

Matthyssens, P., Vandenbempt, K., \& Berghman, L. (2006). Value innovation in business markets: Breaking the industry recipe. Industrial Marketing Management, 35(6), $751-761$.

McCracken, G. (1988). The Long Interview (Qualitative Research Methods Series 13). Newbury Park, CA: Sage.

Neu, W., \& Brown, S. (2005). Forming successful business-to-business services in goodsdominant firms. Journal of Service Research, 8(1), 3-17.

Newbert, S. L. (2005). New firm formation: A dynamic capability perspective. Journal of Small Business Management, 43(1), 55-77. 
Penttinen, E., \& Palmer, J. (2007). Improving firm positioning through enhanced offerings and buyer-seller relationships. Industrial Marketing Management, 36(5), 552-564.

Stefano Di, G., Peteraf, M., \& Gianmiaro, V. (2010). Dynamic capabilities deconstructed: A bibliographic investigation into the origins, development and future direction of the research domain. Industrial and Corporate Change, 19(4), 1187-1204.

Priem, R. L., \& Butler, J. E. (2001). Is the resource-based "view" a useful perspective for strategic management research? Academy of Management Review, 26(1), 22-40.

Rust, R. T., \& Cooil, B. (1994). Reliability measures for qualitative data: Theory and implications. Journal of Marketing Research, 31(February), 1-14.

Sawhney, M., Balasubramanian, S., \& Krishnan, V. V. (2003). Creating growth with services. MIT Sloan Management Review, 45(2), 34-44.

Shepherd, C., \& Ahmed, P. K. (2000). From product innovation to solutions innovation: A new paradigm for competitive advantage. European Journal of Innovation Management, 3(2), 100-106.

Sjödin, D. R., Parida, V., \& Kohtamäki, M. (2016). Capability configurations for advanced service offerings in manufacturing firms: Using fuzzy set qualitative comparative analysis. Journal of Business Research, 69(11), 5330-5335.

Storbacka, K. (2011). A solution business model: Capabilities and management practices for integrated solutions. Industrial Marketing Management, 40(5), 699-711.

Storbacka, K., Windahl, C., Nenonen, S., \& Salonen, A. (2013). Solution business models: Transformation along four continua. Industrial Marketing Management, 42(5), $705-716$.

Strauss, A., \& Corbin, J. (1998). Basics of qualitative research: Procedures and techniques for developing grounded theory (2nd ed.). Thousand Oaks, CA: Sage.

Teece, D. J. (2007). Explicating dynamic capabilities: The nature and microfoundations of (sustainable) enterprise performance. Strategic Management Journal, 28(13), 1319-1350.

Teece, D. J., Pisano, G., \& Shuen, A. (1997). Dynamic capabilities and strategic management. Strategic Management Journal, 18(7), 509-533.

Tuli, K. R., Kohli, A. K., \& Bharadwaj, S. G. (2007). Rethinking customer solutions: From product bundles to relational processes. Journal of Marketing, 71(3), 1-17.

Ulaga, W., \& Reinartz, W. J. (2011). Hybrid offerings: How manufacturing firms combine goods and services successfully. Journal of Marketing, 75(6), 5-23.

Wang, C. L., \& Ahmed, P. K. (2007). Dynamic capabilities: A review and research agenda. International Journal of Management Reviews, 9(1), 31-51.

Weerawardena, J., \& O'Cass, A. (2004). Exploring the characteristics of the market-driven firms and antecedents to sustained competitive advantage. Industrial Marketing Management, 33(5), 419-428.

Wilden, R., Gudergan, S. P., Nielsen, B. B., \& Lings, I. (2013). Dynamic capabilities and performance: Strategy, structure and environment. Long Range Planning, 46(1), 72-96.

Windahl, C., Andersson, P., Berggren, C., \& Nehler, C. (2004). Manufacturing firms and integrated solutions: Characteristics and implications. European Journal of Innovation Management, 7(3), 218-228.

Windahl, C., \& Lakemond, N. (2006). Developing integrated solutions: The importance of relationships within the network. Industrial Marketing Management, 35(7), 806-818.

Windahl, C., \& Lakemond, E. (2010). Integrated solutions from a service-centered perspective: Applicability and limitations in the capital goods industry. Industrial Marketing Management, 39(8), 1278-1290.

Winter, S. G. (2003). Understanding dynamic capabilities. Strategic Management Journal, 24(10), 991-995.

Yin, R. K. (1994). Case study research: Design and methods (2nd ed.). Newbury Park, CA: Sage Publications.

Zahra, S. A., \& George, G. (2002). Absorptive capacity: A review, reconceptualization, and extension. Academy of Management Review, 27(2), 185-203.

Zahra, S. A., Sapienza, H. J., \& Davidsson, P. (2006). Entrepreneurship and dynamic capabilities: A review, model and research agenda. Journal of Management Studies, 43(4), 917-955.

Zollo, M., \& Winter, S. G. (2002). Deliberate learning and the evolution of dynamic capabilities. Organization Science, 13(3), 339-351. 